\author{
聚乙二醇负载的二茂铁噁唑啉配体的合成及其应用 \\ 刘洪强 $a, b \quad$ 时䂞 ${ }^{a}$ 陈庆安 ${ }^{a}$ 王䂞*, ${ }^{a}$ 周永贵*, $a$ \\ ( ${ }^{a}$ 中国科学院大连化学物理研究所 大连 116023) \\ ( ${ }^{b}$ 淮北师范大学 淮北市 235000)
}

\begin{abstract}
摘要 报道了聚乙二醇( MeO-PEG) 负载的二茂铁噁唑啉衍生的手性 $N, P$ 和 $N, S$ 配体的合成. 所得负载 $N, P$ 配体可以成 功应用于银催化的 $[3+2]$ 环加成反应, 最高取得了 $97 \%$ 的对映选择性. 另外聚乙二醇负载二茂铁 $N, S$ 配体可以成功应用 于钯催化的烯丙基取代反应, 取得了 $90 \%$ 的 $e e$ 值. 值得注意是, 聚乙二醇负载形成的催化剂循环使用 4 次后其催化活 性和选择性仍可基本保持.
\end{abstract}

关键词 聚乙二醇; 二茂铁噁唑啉; 不对称催化

\title{
Synthesis of MeO-PEG-Supported Ferrocenyloxazoline Ligands and Their Application in Asymmetric Catalysis
}

\author{
Liu, Hongqiang ${ }^{a, b} \quad$ Shi, Lei $^{a} \quad$ Chen, Qingan ${ }^{a} \quad$ Wang, Lei* ${ }^{*} \quad$ Zhou, Yonggui*,a \\ ( ${ }^{a}$ Dalian Institute of Chemical Physics, Chinese Academy of Sciences, Dalian 116023, China) \\ ( ${ }^{b}$ Huaibei Normal University, Huaibei 235000, China)
}

\begin{abstract}
A simple synthesis of ferrocenyloxazoline derived chiral $N, P$ ligands and $N, S$ ligands immobilized on a MeOPEG-support is described. The metal complexes of chiral ligands have been successfully applied to 1,3-dipolar cycloaddition reaction of azomethine ylides and asymmetric allylic substitution reaction, providing the products with up to $97 \%$ ee and $90 \%$ $e e$, respectively. The MeO-PEG-supported metal complex catalysts can be recycled easily and reused.

Keywords PEG; ferrocenyloxazoline ligands; asymmetric catalysis
\end{abstract}

\section{Introduction}

Recently, asymmetric catalysis with polymer-supported transition metal has attracted a great of interest. ${ }^{[1]} \mathrm{A}$ prominent advantage of immobilized chiral catalysts lied in easy catalyst separation and recycle. However, the immobilized ligands or catalysts which were not dissolved in common solvents often display lower enantioselectivity and less efficiency in their catalysis in comparison with their parent counterparts. So soluble polymer-reagents and catalysts have achieved wide recognition and acclaim because that reactions are carried out homogeneously which can lead to the higher rates and better enantioselectivities than catalysts immobilized on solids, and catalyst could be separated from the reaction mixture by filtration, precipitation or extraction. ${ }^{[2,3]}$

As soluble polymer modified poly(ethylene glycol)s (PEGs) recently emerged as readily functionalized, commercially available polymers that are soluble in some solvents and insoluble in a few other solvents for example ether and $n$-hexane. ${ }^{[4-13]}$ Recently, the monomethyl ether of PEG (MeO-PEG) has successfully being used for supporting chiral ligands to be transformed in catalysts for some catalytic asymmetric reactions. MeO-PEG has also been employed by us for the immobilization of MeO-PEGsupported tunable axial chiral bisphosphine ligands which were applied in asymmetric hydrogenation of quinolines with up to $92 \% e e .^{[14]}$ The catalyst system is air-stable and recyclable.

Recently, ferrocenyloxazoline-based chiral ligands have attracted considerable attention in the past decade due to their ease of preparation, modularity and favorable coordinating properties towards a large variety of metals. ${ }^{[15-17]}$ Among them, planar chiral ferrocenyloxazoline derived chiral $N, P$ ligands and $N, S$ ligands are versatile, and have a wide range of applications in asymmetric catalysis. Very recently, our group mainly focused on chiral bifunctional $\mathrm{AgOAc}$ catalyzed asymmetric reactions under the mild neutral condition, ${ }^{[18-20]}$ for examples, asymmetric 1,3-dipolar cycloaddition reaction of azomethine ylides, asymmetric Mannich-type reactions and asymmetric aminations. ${ }^{[21-25]}$ Among these reactions, ferrocene-derived chiral $N, P$ and $N, S$ ligands gave the excellent reactivity and enantioselectivity. Furthermore, to the best of our knowledge, few examples on soluble polymer supported ferrocenyloxazoline derived chiral $N, P$ and $N, S$ ligands is

*E-mail: ygzhou@dicp.ac.cn; leiwang@chnu.edu.cn

Received November 1, 2012; published December 10, 2012.

Supporting information for this article is available free of charge via the Internet at http://sioc-journal.cn.

Project supported by the National Natural Science Foundation of China (Nos. 21202162 \& 21125208) and the National Basic Research Program of China (No. 2010CB833300).

项目受国家自然科学基金(Nos. 21202162 and 21125208)和国家重大基础研究项目(No. 2010CB833300)资助. 
reported. ${ }^{[26,27]}$ To increase the synthetic utility and practicability of these effective ligands in asymmetric catalysis, herein, we report the facile synthesis of soluble polymer MeO-PEG supported ferrocenyloxazoline-derived chiral $N, P$ and $N, S$ ligands (Figure 1) and their applications in 1,3-dipolar cycloaddition reaction and asymmetric allylic substitution reaction. ${ }^{[28,29]}$

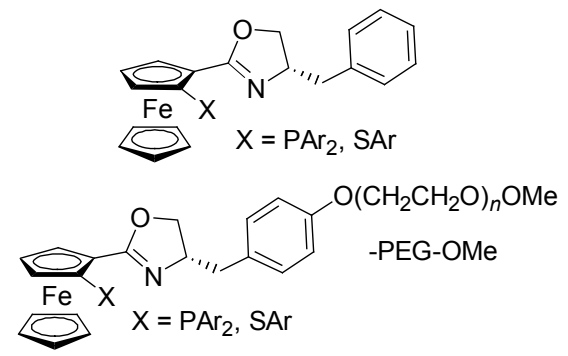

Figure 1 MeO-PEG supported $N, P$ and $N, S$ ligands

\section{Results and discussions}

To incorporate the ferrocenyloxazoline ligands into polymer, an additional functional group on the phenyl ring was required, we tried to attach the soluble polymer to 4-position of the phenyl ring. So, the chiral amino alcohol 5 bearing the source of chirality and a function for further linkage to a polymer is the key intermediate. According to a recently published similar procedure ${ }^{[30,31]}(L)$-Tyrosine is chosen as the starting material, methyl esterification and protection of amino group gave 2 . Then the phenolic hydroxyl group was selectively protected using the TBS, following by reduction by $\mathrm{LiAlH}_{4}$ and removal of the Boc-protecting group to afford the chiral amino alcohol 5 (Figure 2).

According to the known literature procedure, ${ }^{[32]}$ TBS protected oxazoline $\mathbf{6}$ was conveniently synthesized from ferrocene carboxylic acid and chiral amino alcohol $\mathbf{5}$. ortho-Lithiation of oxazoline $\mathbf{6}$ was investigated using $n$-BuLi in $\mathrm{Et}_{2} \mathrm{O}$ at $-78{ }^{\circ} \mathrm{C}$, followed by addition of $\mathrm{Ar}_{2} \mathrm{PCl}$ to give the compounds 7 in moderate yields. Then protective group of TBS was removed with TBAF in THF, followed by reaction with poly(ethylene glycol)s 1900 monomethyl ether mesylate in the presence of $\mathrm{Cs}_{2} \mathrm{CO}_{3}$ in DMF, giving the PEG supported chiral $N, P$ ligands $\mathbf{8 a}-\mathbf{8 b}$ in $47 \%-81 \%$ yields (Figure 3 ). At the same time, chiral ferrocenyloxazoline derived $N, S$ ligand $8 \mathbf{c}$ was also synthesized using the similar literature procedure. ${ }^{[33]}$

As is known, the pyrrolidine ring is widely present in many biologically active compounds and pharmaceuticals. Furthermore, pyrrolidines are important building blocks in organic synthesis, and have emerged as core structure of privileged organocatalysts in the past years. The $[3+2]$ cycloaddition reaction of azomethine ylide with olefinic dipolarophiles constitutes a straightforward approach to the synthesis of highly substituted chiral pyrrolidine derivatives. $^{[34-50]}$ So far, many laboratories have reported the catalytic asymmetric [3+2] cycloadditions with azomethine ylides by means of a variety of ligand-metal combinations. Our group reported that the ferrocenyloxazoline derived chiral $N, P$ ligand showed excellent performance in the $\mathrm{Ag}(\mathrm{I})$-catalyzed enantioselective 1,3-dipolar cycloaddition of azomethine ylides.

To find out whether the MeO-PEG-supported chiral ligands have any influence on the outcome of the reaction, we first tested ligands $\mathbf{8 a}$ in the AgOAc-catalyzed 1,3-dipolar cycloaddition reaction between iminoester 9a and $N$-phenylmaleimide in toluene. To our delight, we found the cycloaddition reaction finished in $3 \mathrm{~h}$ with high activity and excellent enantioselectivity (Entry 1, Table 1). Subsequently, the effect of solvents was examined, and

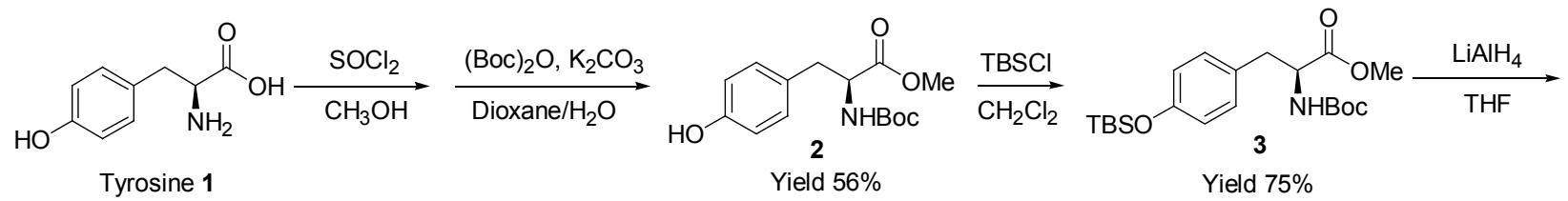

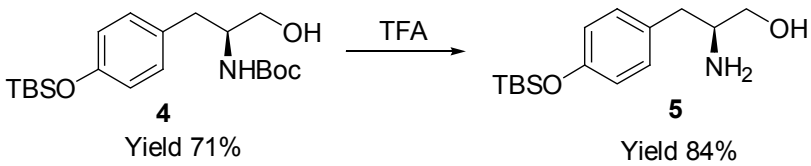

Figure 2 Synthesis of chiral amino alcohol 5

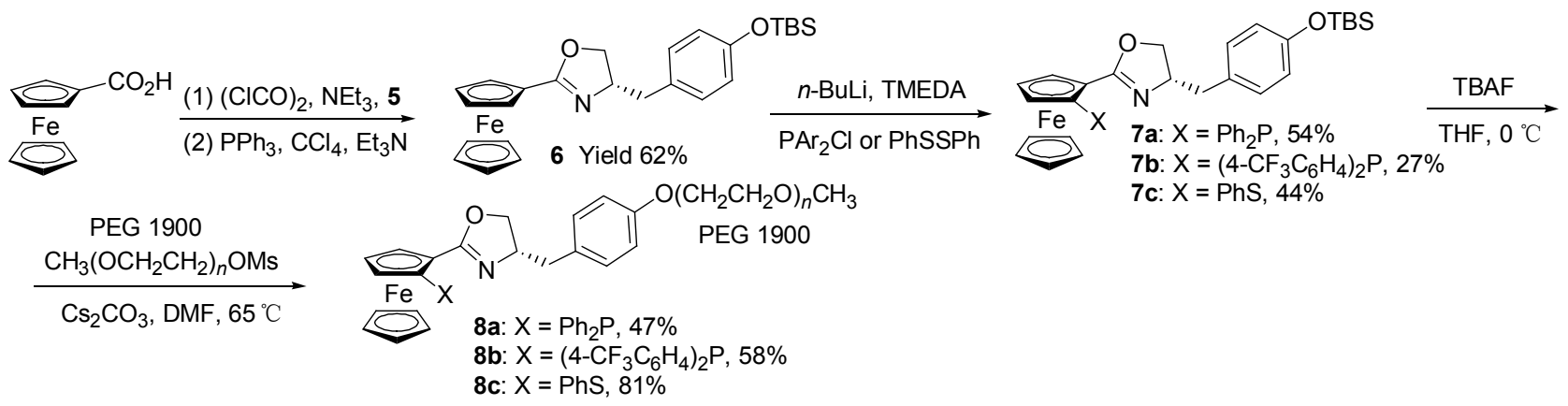

Figure 3 Synthesis of MeO-PEG-supported ligands 8 
found THF was the best solvent in view of reactivity and enantioselectivity (Entry 2). So, we selected THF as solvent and examined effect of ligands and temperature. Gratifyingly, an improvement in enantioselectivity $(97 \%$ $e e$, Entry 5) was observed with ligand $\mathbf{8 b}$ bearing a strong electron-withdrawing trifluoromethyl at the para position of the phenyl ring, which is in agreement with our previous result. The slightly lower ees were obtained at $0{ }^{\circ} \mathrm{C}$ (Entries 6-7). Thus, the optimal conditions for asymmetric cycloaddition of azomethine ylides were AgOAc, $8 \mathbf{b}$, THF and $25{ }^{\circ} \mathrm{C}$.

Table 1 Enantioselective 1,3-dipolar cycloaddition of azomethine ylides

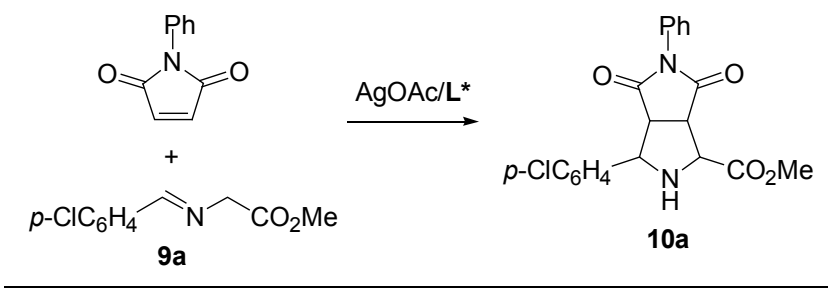

\begin{tabular}{ccccccc}
\hline Entry $^{a}$ & Ligand & Solvent & Temp. $/{ }^{\circ} \mathrm{C}$ & Time $/ \mathrm{h}$ & Yield $^{b} \%$ & $e e^{c} / \%$ \\
\hline 1 & $\mathbf{8 a}$ & Toluene & 25 & 3 & 83 & 92 \\
2 & $\mathbf{8 a}$ & $\mathrm{THF}$ & 25 & 4 & 76 & 93 \\
3 & $\mathbf{8 a}$ & $\mathrm{CH}_{2} \mathrm{Cl}_{2}$ & 25 & 4 & 70 & 89 \\
4 & $\mathbf{8 a}$ & $\mathrm{Et}_{2} \mathrm{O}$ & 25 & 20 & 64 & 94 \\
5 & $\mathbf{8 b}$ & $\mathrm{THF}$ & 25 & 4 & 95 & 97 \\
6 & $\mathbf{8 a}$ & $\mathrm{THF}$ & 0 & 8 & 89 & 91 \\
7 & $\mathbf{8 b}$ & $\mathrm{THF}$ & 0 & 8 & 92 & 97 \\
\hline
\end{tabular}

${ }^{a}$ Conditions: iminoester (1.0 equiv.), $N$-phenylmaleimide (1.5 equiv.), $\mathrm{AgOAc}$ ( $3 \mathrm{~mol} \%)$, ligand $(3.3 \mathrm{~mol} \%)$, concentration $(0.12 \mathrm{~mol} / \mathrm{L}) .{ }^{b}$ Isolated yields. ${ }^{c}$ Determined by HPLC.

On the basis of the optimized reaction conditions, we investigated a variety of iminoester substrates derived from aldehydes with a variety of steric and electronic properties (Table 2). High yields and excellent enantioselectivities were achieved in all of the reactions. The cycloaddition of 9a gave the best $97 \%$ enantioselectivity and $95 \%$ isolated yield (Entry 1). For iminoester bearing no substituent, electron-withdrawing substituent, or electron-donating substituent on the benzene ring, the reaction proceeded smoothly in excellent yields and enantioselectivities (Entries 2-4). As for imines bearing an ortho group on the benzene ring, the corresponding 1,3-dipolar cycloaddition adducts were obtained in $94 \% e e$ and $90 \%$ ee, respectively (Entries 5-6). It is noteworthy that the almost identical enantioselectivity was obtained for the reaction of $\mathbf{9 b}$ with the ligand $\mathbf{8 b}$ and its non-supported mother ligand (Entry $2,92 \%$ vs. $93 \%$ ).

Then, the recovery and reuse of the MeO-PEGsupported chiral ligand $\mathbf{8 b}$ was studied. We chose the 1,3-dipolar cycloaddition of iminoester 9a with $N$-phenylmaleimide in THF at room temperature (Table 3 ). Because MeO-PEG supported ligands $\mathbf{8 b}$ could not dissolve in $\mathrm{Et}_{2} \mathrm{O}$ and the desired product could dissolve in $\mathrm{Et}_{2} \mathrm{O}$, we removed the solvent by oil pump when reaction was completed. Then the system was washed by $\mathrm{Et}_{2} \mathrm{O}$ until no product was tested under an inert atmosphere. The recovered catalyst could be recycled for four times nearly without a loss in enantioselectivity. It is noteworthy that the
Table 2 Enantioselective 1,3-dipolar cycloaddition of azomethine ylides<smiles>O=C1C=CC(=O)N1c1ccccc1</smiles><smiles>[R]C=[N+]CC(C)=O</smiles><smiles>[R]C1NC(C(C)=O)C2C(=O)N(c3ccccc3)C(=O)C12</smiles>

\begin{tabular}{ccccc}
\hline Entry $^{a}$ & $\mathrm{R}$ & Time/h & $\mathrm{Yield}^{b} \%$ & $e e^{c} / \%$ \\
\hline 1 & $4-\mathrm{ClC}_{6} \mathrm{H}_{4}$ & 2 & $95(\mathbf{1 0 a})$ & 97 \\
2 & $\mathrm{Ph}$ & 2 & $90(\mathbf{1 0 b})$ & $92(93)^{d}$ \\
3 & $4-\mathrm{MeC}_{6} \mathrm{H}_{4}$ & 4 & $84(\mathbf{1 0 c})$ & 95 \\
4 & $4-\mathrm{FC}_{6} \mathrm{H}_{4}$ & 2 & $93(\mathbf{1 0 d})$ & 92 \\
5 & $2-\mathrm{MeC}_{6} \mathrm{H}_{4}$ & 4 & $86(\mathbf{1 0 e})$ & 94 \\
6 & $2-\mathrm{ClC}_{6} \mathrm{H}_{4}$ & 4 & $92(\mathbf{1 0 f})$ & 90 \\
\hline
\end{tabular}

${ }^{a}$ Conditions: iminoester (1.0 equiv.), $N$-phenylmaleimide (1.5 equiv.), AgOAc (3 mol\%), $8 \mathbf{b}(3.3 \mathrm{~mol} \%)$, concentration $(0.12 \mathrm{~mol} / \mathrm{L}) .{ }^{b}$ Isolated yields. ${ }^{c}$ Determined by HPLC. ${ }^{d}$ The number in parenthesis was obtained with the non-supported $N, P$ ligand. For the detailed information, please see reference [21].

Table 3 Recycling experiments

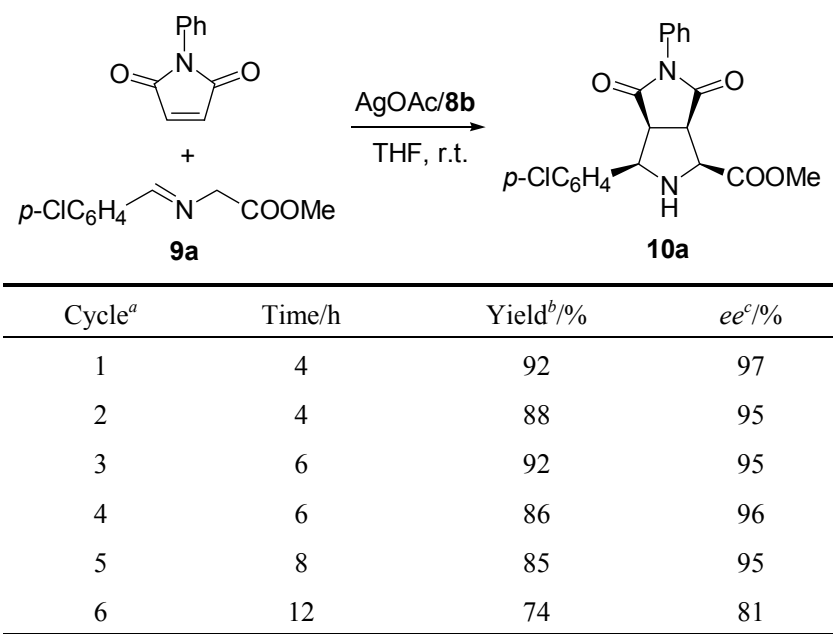

${ }^{a}$ Conditions: iminoester (1.0 equiv.), $N$-phenylmaleimide (1.5 equiv.), AgOAc (3 mol\%), $8 \mathbf{b}(3.3 \mathrm{~mol} \%)$, concentration $(0.12 \mathrm{~mol} / \mathrm{L}) .{ }^{b}$ Isolated yields. ${ }^{c}$ Determined by HPLC.

activity slightly decreased, the reaction times were properly prolonged for the satisfied yields (Entries 1-5). But when the catalyst was run in the sixth time, the activities and enantioselectivities decreased remarkably (Entry 6).

The Pd-catalyzed asymmetric allylic substitution is one of the most versatile routes for preparing optically active compounds through carbon-carbon or carbon-heteroatom bond formation. ${ }^{[28,29]}$ Sulfur-nitrogen ligands have recently been proved to be successful in asymmetric allylic substitution. ${ }^{[51]}$ Encouraged by the excellent results obtained in the 1,3-dipolar cycloadditions, we decided to test the catalytic performance of the polymer-supported ferrocenyloxazoline derived $N, S$ ligand $\mathbf{8 c}$ in this reaction. The reaction of $(E)$-1,3-diphenylallyl acetate with dimethyl malonate was proceeded in $\mathrm{CH}_{2} \mathrm{Cl}_{2}$ using $[\mathrm{Pd}(\text { allyl }) \mathrm{Cl}]_{2}(2.5$ $\mathrm{mol} \%) / 8 \mathrm{c}(6 \mathrm{~mol} \%)$ as catalyst and $\mathrm{N}, \mathrm{O}$-bis(trimethylsilyl)acetamide (BSA) and lithium acetate as base, respectively (Table 4). To our delight, the catalyst still kept its 
good enantioselectivity even after being recovered and reused five times. The activity only decreased remarkably in the sixth time.

Table 4 Pd-catalyzed asymmetric allylic alkylation

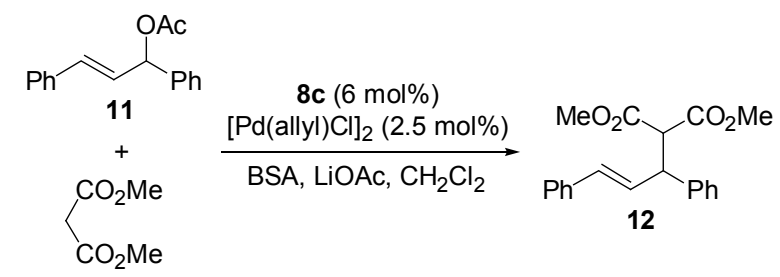

\begin{tabular}{cccc}
\hline Cycle $^{a}$ & Time/h & Yield $^{b} / \%$ & $e e^{c} / \%$ \\
\hline 1 & 2 & 95 & 90 \\
2 & 2 & 94 & 90 \\
3 & 4 & 96 & 88 \\
4 & 4 & 94 & 88 \\
5 & 4 & 85 & 86 \\
6 & 12 & 78 & 85 \\
\hline
\end{tabular}

${ }^{a}$ Conditions: $1 \mathrm{mmol}$ of 11, dimethylmalonate (3 equiv.), $[\mathrm{Pd}(\text { allyl }) \mathrm{Cl}]_{2}(2.5$ mol\%), 8c (6 mol $\%)$, LiOAc (5 mol\%), BSA (3 equiv.), r.t. ${ }^{b}$ Isolated yields. ${ }^{c}$ Determined by HPLC.

\section{Conclusions}

In summary, we have developed an efficient method for the facile synthesis of MeO-PEG-supported ferrocenyloxazoline derived chiral $N, P$ and $N, S$ ligands. These ligands have been successfully applied in asymmetric Ag-catalyzed 1,3-dipolar cycloadditions of azomethine ylides and the Pd-catalyzed asymmetric allylic alkylation with up to $97 \%$ ee and $90 \%$ ee, respectively. Furthermore, the MeO-PEG-supported ferrocenyloxazoline ligands can be recovered and reused.

\section{References}

[1] Leadbeater, N. E.; Marco, M. Chem. Rev. 2002, 102, 3217.

[2] Dickerson, T. J.; Reed, N. N.; Janda, K. D. Chem. Rev. 2002, 102, 3325.

[3] Bergbreiter, D. E. Chem. Rev. 2002, 102, 3345.

[4] Gravert, D. J.; Janda, K. D. Chem. Rev. 1997, 97, 489.

[5] Han, H. S.; Janda, K. D. J. Am. Chem. Soc. 1996, $118,7632$.

[6] Reger, T. S.; Janda, K. D. J. Am. Chem. Soc. 2000, 122, 6929.

[7] Fan, Q. H.; Deng, G. J.; Lin, C. C.; Chan, A. S. C. Tetrahedron: Asymmetry 2001, 12, 1241.

[8] Li, X. G.; Chen, W. P.; Hems, W.; King, F.; Xiao, J. L. Org. Lett. 2003, 5,4559

[9] Gissibl, A.; Finn, M. G.; Reiser, O. Org. Lett. 2005, 7, 2325.

[10] Xu, L.; Lam, K. H.; Ji, J.; Wu, J.; Fan, Q.-H.; Lo, W.-H.; Chan, A. S. C. Chem. Commun. 2005, 1390.

[11] Yang, X. W.; Liu, H. Q.; Xu, M. H.; Lin, G. Q. Chin. J. Chem. 2005, 23, 68 .

[12] Hu, X. P.; Huang, J. D.; Zeng, Q. H.; Zheng, Z. Chem. Commun. 2006, 293.
[13] Bandini, M.; Benaglia, M.; Sinisi, R.; Tommasi, S.; Umani-Ronchi, A. Org. Lett. 2007, 9, 2151.

[14] Wang, X. B.; Zhou, Y. G. J. Org. Chem. 2008, 73, 5640.

[15] Dai, L. X.; Tu, T.; You, S. L.; Deng, W. P.; Hou, X. L. Acc. Chem. Res. 2003, 36, 659.

[16] Arrayas, R. G.; Adrio, J.; Carretero, J. C. Angew. Chem., Int. Ed. 2006, 45,7674

[17] Hargaden, G. C.; Guiry, P. J. Chem. Rev. 2009, 109, 2505.

[18] Naodovic, M.; Yamamoto, H. Chem. Rev. 2008, 108, 3132.

[19] Yanagisawa, A.; Arai, T. Chem. Commun. 2008, 1165.

[20] Chen, Q. A.; Wang, D. S.; Zhou, Y. G. Chem. Commun. 2010, 46, 4043

[21] Zeng, W.; Zhou, Y. G. Org. Lett. 2005, 7, 5055.

[22] Zeng, W.; Chen, G. Y.; Zhou, Y. G.; Li, Y. X. J. Am. Chem. Soc. 2007, 129, 750

[23] Zeng, W.; Zhou, Y. G. Tetrahedron Lett. 2007, 48, 4619

[24] Chen, Q. A.; Zeng, W.; Wang, D. W.; Zhou, Y. G. Synlett 2009, 2236.

[25] Chen, Q. A.; Zeng, W.; Zhou, Y. G. Tetrahedron Lett. 2009, 50, 6866.

[26] Bolm, C.; Hermanns, N.; Classen, A.; Muniz, K. Bioorg. Med. Chem. Lett. 2002, 12, 1795 .

[27] Martin-Matute, B.; Isabel Pereira, S.; Pena-Cabrera, E.; Adrio, J.; Silva, A. M. S.; Carretero, J. C. Adv. Synth. Catal. 2007, 349, 1714.

[28] Trost, B. M. Chem. Pharm. Bull. 2002, 50, 1.

[29] Trost, B. M.; Crawley, M. L. Chem. Rev. 2003, 103, 2921.

[30] Deng, H. B.; Jung, J. K.; Liu, T.; Kuntz, K. W.; Snapper, M. L.; Hoveyda, A. H. J. Am. Chem. Soc. 2003, 125, 9032.

[31] Liao, L. A.; Zhang, F.; Dmitrenko, O.; Bach, R. D.; Fox, J. M. J. Am. Chem. Soc. 2004, 126, 4490.

[32] Richards, C. J.; Mulvaney, A. W. Tetrahedron: Asymmetry 1996, 7, 1419.

[33] You, S. L.; Zhou, Y. G.; Hou, X. L.; Dai, L. X. Chem. Commun. 1998, 2765

[34] Gothelf, K. V.; Jorgensen, K. A. Chem. Rev. 1998, 98, 863.

[35] Pandey, G.; Banerjee, P.; Gadre, S. R. Chem. Rev. 2006, 106, 4484

[36] Stanley, L. M.; Sibi, M. P. Chem. Rev. 2008, 108, 2887.

[37] Gothelf, A. S.; Gothelf, K. V.; Hazell, R. G.; Jorgensen, K. A. Angew. Chem., Int. Ed. 2002, 41, 4236.

[38] Longmire, J. M.; Wang, B.; Zhang, X. M. J. Am. Chem. Soc. 2002, 124,13400 .

[39] Chen, C.; Li, X. D.; Schreiber, S. L. J. Am. Chem. Soc. 2003, 125, 10174.

[40] Cabrera, S.; Arrayas, R. G.; Carretero, J. C. J. Am. Chem. Soc. 2005 $127,16394$.

[41] Saito, S.; Tsubogo, T.; Kobayashi, S. J. Am. Chem. Soc. 2007, 129, 5364.

[42] Chen, X. H.; Zhang, W. Q.; Gong, L. Z. J. Am. Chem. Soc. 2008, $130,5652$.

[43] Shi, J. W.; Zhao, M. X.; Lei, Z. Y.; Shi, M. J. Org. Chem. 2008, 73, 305.

[44] Najera, C.; Retamosa, M. D.; Sansano, J. M. Angew. Chem., Int. Ed. 2008, 47,6055 .

[45] Wang, C. J.; Liang, G.; Xue, Z. Y.; Gao, F. J. Am. Chem. Soc. 2008, $130,17250$.

[46] Wang, C. J.; Xue, Z. Y.; Liang, G.; Lu, Z. Chem. Commun. 2009, 2905

[47] Xue, Z. Y.; Liu, T. L.; Lu, Z; Huang, H.; Tao, H. Y.; Wang, C. J. Chem. Commun. 2010, 1727.

[48] Kim, H. Y.; Shih, H. J.; Knabe, W. E.; Oh, K. Angew. Chem., Int. Ed. 2009, 48, 7420.

[49] Arai, T.; Mishiro, A.; Yokoyama, N.; Suzuki, K.; Sato, H. J. Am. Chem. Soc. 2010, 132, 5338.

[50] Yamashita, Y.; Imaizumi, T.; Kobayashi, S. Angew. Chem., Int. Ed. 2011, 50, 4893 .

[51] You, S. L.; Hou, X. L.; Dai, L. X.; Yu, Y. H.; Xia, W. J. Org. Chem. 2002, 67, 4684 . 